\title{
Overweight in family members of probands with ADHD
}

\author{
Pauline M. Geuijen ${ }^{1,2}$ - Jan K. Buitelaar ${ }^{1,3}$. Ellen A. Fliers ${ }^{4,5}$. Athanasios Maras ${ }^{5}$. Lizanne J. S. Schweren ${ }^{6}$. \\ Jaap Oosterlaan ${ }^{7,8,9} \cdot$ Pieter J. Hoekstra ${ }^{6,10}$ - Barbara Franke ${ }^{2,11} \cdot$ Catharina A. Hartman ${ }^{6} \cdot$ Nanda N. Rommelse $^{1,2}$
}

Received: 29 January 2019 / Accepted: 1 April 2019 / Published online: 19 April 2019

(c) The Author(s) 2019

\begin{abstract}
The widely reported association between ADHD and overweight may be attributable to genetic and environmental factors also present in unaffected family members. Therefore, the purpose of this study was to examine the association between ADHD and overweight within families. A cohort was used of families with at least one member with ADHD, recruited as part of the Dutch node of the International Multicenter ADHD Genetics (IMAGE) study, with assessments taking place between 2003 and 2006, 2009 and 2012, and 2013 and 2015. The three assessment waves yielded $N=1828$ youth assessments and $N=998$ parent assessments from $N=447$ unique families. Overweight was defined as a body mass index (BMI) $\geq 85$ th percentile for youth of the same age and sex; overweight in adults as a BMI $\geq 25$. Effects of age, gender, and medication use (psychostimulants, antipsychotics, and melatonin) were taken into account. Generalized estimation equations were used to correct for within-family and within-subject correlations. There was no difference in risk between ADHD-affected youth and their unaffected siblings (OR 0.92, 95\% CI 0.78-1.09). However, compared to population prevalence data, all ADHD family members alike were at increased risk for being overweight: ADHD-affected youth (OR 1.33, 95\% CI 1.13-1.59), unaffected siblings (OR 1.73, 95\% CI 1.45-2.08), mothers (OR 1.74, 95\% CI 1.40-2.17) and fathers (OR 1.78, 95\% CI 1.46-2.15). Parental overweight—but not parental ADHD—was predictive of offspring overweight (mothers OR 1.40; 95\% CI 1.14-1.73, fathers OR 1.83; 95\% CI 1.41-2.36). Being overweight runs in ADHD families, yet is not specifically linked to ADHD within families. Shared unhealthy lifestyle factors (including nutrition, sleep, exercise, stress) as well as genetic factors shared by family members likely explain the findings.
\end{abstract}

Keywords Attention-deficit/hyperactivity disorder · Overweight $\cdot$ Family $\cdot$ Child $\cdot$ Adolescent

Electronic supplementary material The online version of this article (https://doi.org/10.1007/s00787-019-01331-7) contains supplementary material, which is available to authorized users.

Pauline M. Geuijen

paulinegeuijen@gmail.com

1 Karakter Child and Adolescent Psychiatry University Center, Reinier Postlaan 12, 6525 GC Nijmegen, The Netherlands

2 Department of Psychiatry, Donders Institute for Brain, Cognition and Behaviour, Centre for Neuroscience, Radboud University Medical Center, Nijmegen, The Netherlands

3 Department of Cognitive Neuroscience, Donders Institute for Brain, Cognition and Behaviour, Centre for Neuroscience, Radboud University Medical Centre, Nijmegen, The Netherlands

4 Virenze Child and Adolescent Psychiatry, Gorinchem, The Netherlands

5 Yulius Academy, Yulius Mental Health Organization, Barendrecht, The Netherlands
6 Department of Psychiatry, University Medical Center Groningen, University of Groningen, Groningen, The Netherlands

7 Clinical Neuropsychology Section, Vrije Universiteit Amsterdam, Amsterdam, The Netherlands

8 Emma Children's Hospital, Academic Medical Center, Amsterdam, The Netherlands

9 Department of Pediatrics, Vrije Universiteit Medical Center, Amsterdam, The Netherlands

10 Accare University Child and Adolescent Psychiatry Center, Groningen, The Netherlands

11 Department of Human Genetics, Donders Institute for Brain, Cognition and Behaviour, Centre for Neuroscience, Radboud University Medical Center, Nijmegen, The Netherlands 


\section{Introduction}

Is there a relationship between attention-deficit/hyperactivity disorder (ADHD) and being overweight? This has been the central question for many small- and large-scale studies during the last 2 decades. Two recent meta-analyses concluded that people with ADHD have a 20-30\% increased chance of being overweight compared to population prevalence rates $[1,2]$. Inconsistent conclusions were drawn regarding gender effects $[1,2]$. Vice versa, it has also been shown that overweight individuals-compared to individuals with a healthy weight—are more likely to show ADHD symptoms [3-5].

Various mechanisms have been proposed to explain the association between ADHD and overweight. ADHD may causally lead to overweight through impulsive (binge) eating [6] since ADHD is often characterized by emotional lability, impulsivity, and disturbances in sleep and circadian rhythm [7, 8]. There is no direct evidence for this hypothesis, but there is a substantial amount of indirect evidence. The prevalence of binge eating symptoms and bulimia nervosa is higher in patients with ADHD [9]. Similarly, patients with bulimia nervosa have an increased chance of having (a childhood history of) ADHD and executive control problems [10-12]. Alternatively, instead of a causal association between ADHD and overweight, shared etiologies between ADHD and overweight may be key to understanding the association between both. Currently, to the best of our knowledge, one twin and sibling study has directly tested the contribution of shared genetic and environmental factors for both phenotypes in young and older adulthood [13]. They found a significant role for unique environmental influences explaining the association between both phenotypes in males and genetic influences contributing to the association between both phenotypes in females. Similarly, another study also suggested that the association between ADHD and binge eating in females was largely explained by shared genetic risk factors [14], suggesting the mechanisms underlying the association between ADHD and overweight may be different in males and females. Several molecular genetic studies have reported common candidate genes for ADHD and increased BMI [15-17]. In addition, a large-scale genetic correlation between both phenotypes was reported based on genome-wide association studies of common genetic variants, but potential sex moderating effects were not reported [18]. Apart from a shared genetic background, both phenotypes also show very similar relationships with adverse environmental factors such as low socio-economic status, parental psychopathology, and poor nutritional and exercise habits [19-23]. A recent report even argued that the link between ADHD symptoms and increased body weight could be completely explained by cumulative psychosocial risks, and highlighted the importance of chronic stress as a trigger for both conditions [19]. In a recent comprehensive review on potential mechanism explaining the association between ADHD and overweight [24], including genetic factors, fetal programming, executive dysfunctions, psychosocial stress, factors directly related to energy balance, and sleep patterns alterations, it was concluded that physical activity and eating patterns as possible and most direct causes of weight gain do not seem to fully explain the link and need to be integrated in a broader biopsychosocial model. It was proposed that ADHD and obesity might have a common neurocognitive phenotype, characterized by deficits in hot executive functions, associated with impulsivity and difficulties in postponing gratification [24]. Fetal programming is proposed to be an important element in this model, with environmental agents such as maternal stress, maternal smoking, and drinking alcohol during pregnancy disrupting the development of executive functions.

To test this model, this study employs a within-family design to examine mechanisms underlying the association between ADHD and being overweight in ADHD-affected and -unaffected family members taking into account age, gender, and medication use since these have been reported as moderating factors [25-28]. A family-based study design including unaffected family members of patients with ADHD provides unique opportunities. It allows to investigate whether overweight in ADHD is associated with the presence of ADHD or with shared familial factors. If the association between ADHD and overweight is indeed primarily linked to deficits in hot executive functions, characterized by impulsivity and difficulties in postponing gratification, it is expected that overweight will be primarily present in family members meeting criteria for ADHD. However, if the association between ADHD and overweight is primarily explained by factors shared by family members with and without ADHD, a similar increased prevalence of being overweight in family members affected and unaffected by ADHD is expected compared to population prevalence rates. In addition, the predictive effect of parental BMI on child BMI is expected to be larger than the predictive effect of parental ADHD on child BMI. Remarkably and to the best of our knowledge, only one prior study addressed this issue in a family design, albeit indirectly [29]. In a large population-based sample $(N=11,159)$, the association between children's (6-17 years) ADHD symptoms and body mass index (BMI) status was strongly attenuated when parental BMI was accounted for [29]. This may indicate that the association between ADHD symptoms and overweight/obesity is due to confounding by family background. However, parental ADHD symptoms were not taken into account, preventing a direct comparison of the effects of parental BMI and 
parental ADHD status on offspring weight status. One previous study included unaffected siblings for studying the relationship between overweight and ADHD within families [5]. However, parental overweight and ADHD symptoms were not included in this study.

\section{Methods}

\section{Participants}

Families $(N=369)$ were recruited as part of the Dutch node of the International Multicenter ADHD Genetics (IMAGE) study, with assessments taking place between 2003 and 2006 (wave 1), see Figure S1. All families were invited for a second assessment (wave 2), which took place between 2009 and 2012. Follow-up rate was $75.9 \%(N=280$ families). New families $(N=45)$ were recruited at the second assessment wave as well [30]. Recently, a proportion of the families $(N=184)$ was invited for the third assessment (wave 3 ; 2013-2015) with a follow-up rate of $47.3 \%(N=87)$. Again, new families $(N=33)$ were added to the sample. The three assessment waves yielded $N=1828$ youth assessments and $N=998$ parent assessments from $N=447$ unique families, for a description of the full sample see Table 1. A family-based control cohort was available with children (not parents) measured during the same assessment waves comprising a total of $N=361$ assessments from $N=136$ unique families.

Conner's long-version parent and teacher questionnaires (youth $<18$ years) or parent and self-report (youth $\geq 18$ years) were used to screen all youth [31-33]. $T$ scores $\geq 63$ on the DSM-IV ADHD subscale inattention (L), hyperactivity/impulsivity (M), and total symptoms (N) were considered clinical. Youth scoring clinically on any of these subscales were administered a semi-structured, standardized,
Table 1 Sample description of all assessments $(N=1828)$ for all youth individuals $(N=998$; $31.7 \%$ was measured once, $53.5 \%$ was measured twice, $14.8 \%$ was measured three times) within the NeuroIMAGE cohort

\begin{tabular}{|c|c|c|c|c|c|}
\hline & \multicolumn{2}{|c|}{$\begin{array}{l}\text { ADHD-affected youth } \\
\text { assessments }\end{array}$} & \multicolumn{2}{|c|}{$\begin{array}{l}\text { Unaffected youth assess- } \\
\text { ments }\end{array}$} & \multirow{2}{*}{$\begin{array}{l}t \text { test } \\
p \text { value }\end{array}$} \\
\hline & $N$ & $M(\mathrm{SD}) / \%$ & $N$ & $M(\mathrm{SD}) / \%$ & \\
\hline Age in years & 1037 & $14.3(4.3)$ & 791 & $15.3(5.2)$ & $<0.0001$ \\
\hline Male gender & 1037 & 72 & 791 & 45 & $<0.0001 *$ \\
\hline IQ & 997 & 99 (17) & 752 & $104(16)$ & $<0.0001$ \\
\hline \multicolumn{6}{|l|}{ CPRS $T$ scores } \\
\hline Inattentive & 1009 & $68(11)$ & 751 & $50(9)$ & $<0.0001$ \\
\hline Hyperactive & 1010 & $73(14)$ & 752 & $51(11)$ & $<0.0001$ \\
\hline Total & 1010 & $73(12)$ & 752 & $50(10)$ & $<0.0001$ \\
\hline \multicolumn{6}{|l|}{ CORS $T$ scores } \\
\hline Inattentive & 978 & $65(11)$ & 742 & $50(10)$ & $<0.0001$ \\
\hline Hyperactive & 976 & $65(14)$ & 742 & $49(11)$ & $<0.0001$ \\
\hline Total & 977 & $67(12)$ & 742 & $49(10)$ & $<0.0001$ \\
\hline \multicolumn{6}{|c|}{ Parental age in years } \\
\hline Mother & $925^{\mathrm{a}}$ & $43.2(5.3)$ & $665^{\mathrm{a}}$ & $43.9(5.6)$ & 0.0060 \\
\hline Father & $930^{\mathrm{a}}$ & $45.8(6.0)$ & $668^{\mathrm{a}}$ & $46.0(6.1)$ & 0.25 \\
\hline \multicolumn{6}{|c|}{ Parental education in years } \\
\hline Mother & $784^{\mathrm{a}}$ & $11.4(2.3)$ & $593^{\mathrm{a}}$ & $11.3(2.0)$ & 0.20 \\
\hline Father & $660^{\mathrm{a}}$ & $11.6(2.8)$ & $499^{\mathrm{a}}$ & $11.7(2.8)$ & 0.27 \\
\hline \multicolumn{6}{|c|}{ Parental ADHD symptom presence } \\
\hline Mother & $922^{\mathrm{a}}$ & 1.3 & $661^{\mathrm{a}}$ & 0.9 & $0.45^{*}$ \\
\hline Father & $858^{\mathrm{a}}$ & 1.0 & $615^{\mathrm{a}}$ & 0.5 & $0.28 *$ \\
\hline \multicolumn{6}{|c|}{ Parental BMI in $\mathrm{kg} / \mathrm{m}^{2}$} \\
\hline Mother & $726^{\mathrm{a}}$ & $27.3(5.3)$ & $543^{\mathrm{a}}$ & $27.6(5.3)$ & 0.15 \\
\hline Father & $647^{\mathrm{a}}$ & $27.7(4.4)$ & $488^{\mathrm{a}}$ & $27.6(4.5)$ & 0.35 \\
\hline
\end{tabular}

Parental data are presented separately for assessments of ADHD-affected and -unaffected youth, but since at least two children/adolescents per family participated, parental data by definition largely overlaps CPRS Conners' Rating Scale completed by Parents, CORS Conners' Rating Scale completed by Others (teacher or self-report), $N$ number, $M$ mean, $S D$ standard deviation

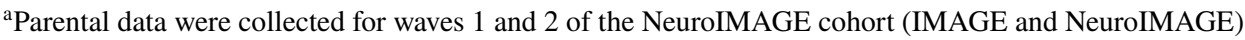
$* \chi^{2}$ test was used 
investigator-based interview: the parental account of children's symptoms (PACS) (wave 1) or the schedule for affective disorders and schizophrenia for school-age childrenpresent and lifetime version (K-SADS [34]; waves 2 and 3 , respectively). ADHD types/presentations (combined, predominantly inattentive, or predominantly hyperactive/ impulsive) were established according to DSM-IV-TR criteria (first assessment) or DSM-5 criteria (second and third assessment) (for full description of diagnostic procedures see [30]).

Self-reported ADHD symptoms in the parents were measured with either the ADHD rating scale (wave 1) [35] or the Conner's self-report (waves 2 and 3) [32]. Ratings were dichotomized into presence (above cut-off) or absence (below cut-off) for ADHD.

\section{Measures}

Body weight and height were measured by professionals in the hospital. The individuals were clothed but wore no shoes or coats. Weight was measured to $0.1 \mathrm{~kg}$ using an electronic flat scale (Seca 877, Seca GmbH \& Co. KG, Hamburg, Germany), height was determined to the nearest $5 \mathrm{~mm}$ using a wall-mounted tape measure (Seca 20, Seca GmbH \& Co. KG, Hamburg, Germany). BMI was calculated as weight in kilograms divided by squared height in meters [36]. The classification of youth and their parents as being overweight (including obesity) was based on sex- and agespecific cut-off values of the World Obesity Federation (formerly known as International Obesity Task Force (IOTF)) $[37,38]$. Briefly, overweight in youth was defined as a BMI at or above the 85th percentile for youth of the same age and sex. In individuals older than 18 years a BMI of 25 or higher defined being overweight. At the third assessment, parental BMI data were not collected. Population prevalence rates of being overweight in youth were obtained from the Fifth National Growth Study, a sample of 12,104 individuals aged 2-21 years measured during 2009-2010 by community health services [39]. Adult population prevalence rates of being overweight were obtained from the Dutch Health Survey 2014, a sample of 3715 adults aged 31-60 years measured by Statistics Netherlands (CBS) [40].

Full-scale IQ of all youth was estimated by four subtests (vocabulary, similarities, block design, and picture completion) of the WISC/WAIS-III (Wechsler Intelligence Scale for Children or Wechsler Adult Intelligence Scale-III) [41].

For ADHD-affected offspring, we recorded the use of psychostimulants (methylphenidate and atomoxetine), antipsychotics (risperidone), and melatonin up to 4 months prior to the assessment day. Preferably, pharmacy transcripts were used to obtain data on medication use (yes/no). If pharmacy records were not available, self-report questionnaires on current and past medication use were used as binary measures.
Socio-economic status was operationalized by the highest successfully completed education of each parent. This scale contained nine levels, ranging from 0 (no formal education) to 9 (university education) [42, 43].

\section{Statistical analyses}

Analyses were performed using the Statistical Package for Social Sciences, version 22.0 for Windows (IBM Corporation, New York, USA). Generalized estimating equations (GEE) were used to correct for within-family and withinsubject correlations (correlated measurements over time). In the first step (default youth model), we predicted youth overweight status (yes/no) by ADHD diagnosis (yes/no), gender (male/female), age (continuous), age ${ }^{2}$ (continuous), and IQ (continuous). In the second step (extended youth model), two-level interactions among predictors were added to the default model predicting youth overweight status (yes/ no); predictors were dropped in case of non-significance. In a third step (parental youth model), the following variables were added to the extended model predicting youth overweight status (yes/no): age parent (continuous), education parent (continuous), ADHD score parent above cut-off (yes/no), and overweight status parent (yes/no). Parental data were only available for a subsample of 539 individuals ( $N=828$ assessments). In the last step (affected youth medication model), for ADHD-affected youth, the extended model predicting youth overweight status (yes/ no) was extended by adding the following predictors: use of psychostimulants (yes/no), antipsychotics (yes/no), and melatonin (yes/no). Two-level interactions among predictors were added to the medication model and dropped in case of non-significance.

Parental overweight was predicted using ADHD above cut-off (yes/no), gender (male/female), age (continuous), and age $^{2}$ (continuous) as predictors (default parent model). Twolevel interactions among predictors were added to the default model and dropped in case of non-significance (extended parent model).

Continuous variables were centered to the median, enabling predictive values to reflect the median population (median youth age $=14.5$ years, median estimated $\mathrm{IQ}=100$, median years of parental education $=10.5$ years, median mother's age $=43.4$ years, median father's age $=45.6$ years). All final probability models were created by backward elimination with a significance level of 0.1. Only for two essential youth variables (IQ and BMI), multiple imputation (20 imputations) was used for missing values $(<15 \%)$.

Estimates of the extended youth and parent probability models were used to plot overweight probabilities stratified by gender (male/female), family member (mother, father, ADHD-affected child, unaffected sibling), and age (continuous). Youth and adult population prevalence were included 
in these plots for reference. For youth, these plots ranged till the age of 21 years since population prevalence data were available for youth till the age of 21 years. Odds ratios were calculated to compare the prevalence of overweight in ADHD-affected family members by the overweight population prevalence. Comparisons to the control family cohort are presented in the supplementary material. Correction for multiple testing was applied using the false discovery rate (FDR) [44].

\section{Results}

Demographics of the sample are shown in Table 1. Compared to the unaffected siblings' assessments, ADHDaffected youth were younger than their unaffected siblings, had lower IQ scores, were more likely male and had-as expected-higher ADHD symptom scores. Parental variables, except for maternal age, were similar for both groups of youth (Table 1). Point prevalence rates of overweight uncorrected for age and sex were 17.6\% (ADHD-affected youth), $22.0 \%$ (unaffected siblings), $60.4 \%$ (mothers) and $72.3 \%$ (fathers).

In relation to the main objective whether or not ADHD is associated with overweight within families, the first step (default youth model) showed no main effect of ADHD status on overweight status (OR 0.92, 95\% CI 0.78-1.09), i.e., youth with and without ADHD were equally likely to be overweight. In the second step (extended youth model), we found a small ADHD status by age interaction effect such that the risk for being overweight increased with age in youth with ADHD but not in unaffected youth (OR 1.04, 95\% CI 1.01-1.07); however, this effect did not survive correction for multiple testing. No other significant or near-significant two-level interactions among predictors were found in the extended model.

In the third step (parental youth model), adding parental variables to the model predicting youth overweight status did not change the predictive value of the default model variables (ADHD diagnosis, gender, age, age ${ }^{2}$, and IQ). Both maternal and paternal overweight predicted overweight in their offspring (mothers OR 1.40; 95\% CI 1.14-1.73, fathers OR 1.83; 95\% CI 1.41-2.36) (Table 2). Maternal education was predictive of offspring overweight (OR 1.05; 95\% CI 1.00-1.10), but this effect did not survive correction for multiple testing. Parental age and ADHD above cut-off were not predictive of being overweight in offspring. In the last step (affected youth medication model), the use of psychostimulants, antipsychotics, or melatonin did not change the predictive value of the default model variables and was not predictive of being overweight in ADHD-affected youth (OR $0.98,95 \%$ CI $0.76-1.26$; OR 0.81, 95\% CI 0.49-1.34; OR
Table 2 Probability models for being overweight in youth within the NeuroIMAGE cohort derived from generalized estimating equations

\begin{tabular}{|c|c|c|}
\hline & OR $(95 \% \mathrm{CI})$ & \\
\hline \multicolumn{3}{|l|}{ Default youth model } \\
\hline Intercept & $0.50(0.43 ; 0.59)^{\mathrm{a}}$ & \\
\hline ADHD diagnosis & $0.93(0.79 ; 1.10)$ & \\
\hline Male gender & $0.73(0.61 ; 0.86)^{\mathrm{a}}$ & \\
\hline Age (centered) & $1.00(1.00 ; 1.03)$ & \\
\hline Age $(\text { centered })^{2}$ & $1.00(1.00 ; 1.01)$ & \\
\hline IQ (centered) & $0.99(0.98 ; 1.01)$ & \\
\hline$N$ assessments & & 1749 \\
\hline \multicolumn{3}{|l|}{ Extended youth model } \\
\hline ADHD diagnosis $\times$ male gender & - & \\
\hline ADHD diagnosis $\times$ age (centered) & $1.04(1.01 ; 1.07)^{\mathrm{a}}$ & \\
\hline Male gender $\times$ age (centered) & - & \\
\hline$N$ assessments & & 1749 \\
\hline \multicolumn{3}{|l|}{ Parental youth model } \\
\hline Maternal age (centered) & - & \\
\hline Paternal age (centered) & - & \\
\hline Maternal education (centered) & $1.05(1.00 ; 1.10)^{\mathrm{a}}$ & \\
\hline Paternal education (centered) & - & \\
\hline Maternal ADHD score above cut-off & - & \\
\hline Paternal ADHD score above cut-off & - & \\
\hline Maternal overweight & $1.40(1.14 ; 1.73)^{\mathrm{a}}$ & \\
\hline Paternal overweight & $1.83(1.41 ; 2.36)^{\mathrm{a}}$ & \\
\hline$N$ assessments & & 828 \\
\hline \multicolumn{3}{|l|}{ Affected youth medication model } \\
\hline Psychostimulant use & $0.98(0.76 ; 1.26)$ & \\
\hline Antipsychotic use & $0.81(0.49 ; 1.34)$ & \\
\hline Melatonin use & $0.74(0.50 ; 1.07)$ & \\
\hline Psychostimulant use $\times$ male gender & - & \\
\hline Psychostimulant use $\times$ age (centered) & - & \\
\hline Antipsychotic use $\times$ male gender & - & \\
\hline Antipsychotic use $\times$ age (centered) & - & \\
\hline Melatonin use $\times$ male gender & - & \\
\hline Melatonin use $\times$ age (centered) & - & \\
\hline$N$ assessments & & 641 \\
\hline
\end{tabular}

${ }^{\text {a }}$ Significant after FDR correction

$0.74,95 \%$ CI $0.50-1.07$, respectively), nor were interactions between them.

Parental overweight (default parent model) was predicted by gender but not age: fathers were found to be more often overweight than mothers (OR 1.40; 95\% CI 1.19-1.66; Table 3). ADHD above cut-off did not predict overweight in parents.

As shown in Figs. 1 and 2 (separately shown for males and females), compared to the national population prevalence estimates, a higher prevalence of being overweight was measured in all groups compared to the normative data: ADHD-affected youth (OR 1.33, 95\% CI 1.13-1.59); 
Table 3 Probability models for being overweight in parents within the NeuroIMAGE cohort derived from Generalized Estimating Equations

\section{OR $(95 \% \mathrm{CI})$}

\section{Default parent model}

Intercept

$1.37(1.21 ; 1.55)$

ADHD score above cut-off

$1.34(0.52 ; 3.46)$

Male gender

Age (centered)

$1.40(1.19 ; 1.66)^{\mathrm{a}}$

Age (centered) $)^{2}$

$1.01(1.00 ; 1.03)$

$1.00(1.00 ; 1.00)$

$N$ assessments

\section{Extended parent model}

ADHD score above cut-off $\times$ male gender -

ADHD score above cut-off $\times$ age (centered)

Male gender $\times$ age (centered)

$N$ assessments

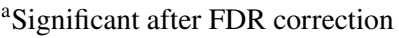

unaffected siblings (OR 1.73, 95\% CI 1.45-2.08); fathers (OR 1.74, 95\% CI 1.40-2.17); mothers (OR 1.78, 95\% CI 1.46-2.15). Findings were similar (albeit less significant) when ADHD-affected youth and unaffected siblings were compared to a consecutively measured control cohort of youth (ADHD: OR 1.12, 95\% CI 0.91-1.38; unaffected siblings: OR 1.73, 95\% CI 1.27-2.34; Tables S4a, S4b, available online).

\section{Discussion}

In a large family-based cohort, we investigated the extent to which associations between ADHD and being overweight are attributable to shared familial factors or specifically linked to ADHD status. We compared the risk of being overweight in individuals with ADHD, their unaffected siblings, and their parents with population normative data and a control family-based cohort. The three assessment waves yielded $N=1828$ youth assessments and $N=998$
Fig. 1 a Males and $\mathbf{b}$ females. Prediction of overweight probability in males and females stratified by ADHD diagnosis $(N=962$ assessments, derived from 571 males, and $N=628$ assessments, derived from 374 females, respectively). Error bars represent $95 \%$ confidence interval for predicted probabilities. Population prevalence of being overweight was derived from the Fifth National Growth Study (2009-2010). Note: prediction of overweight probabilities in adolescents older than 21 years was not included in this figure since there were no reliable reference data available for this age group

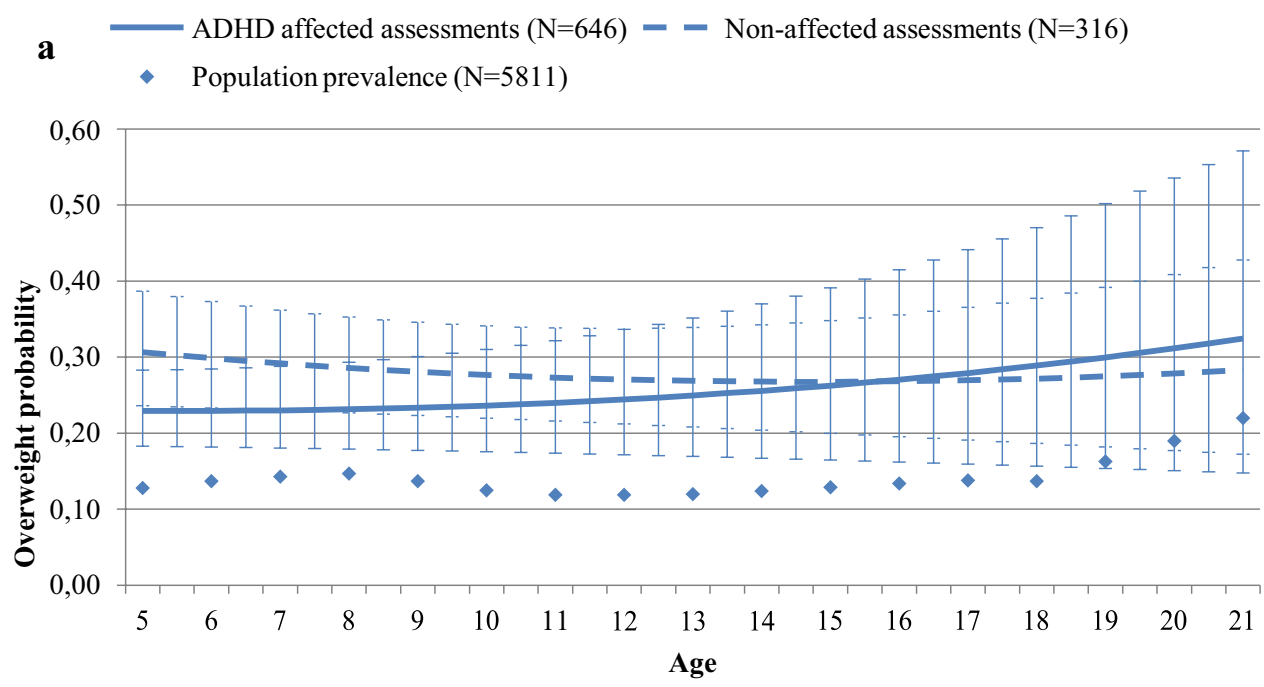

b ADHD affected assessments $(\mathrm{N}=250)-$ Non-affected assessments $(\mathrm{N}=378)$

- Population prevalence $(\mathrm{N}=6194)$

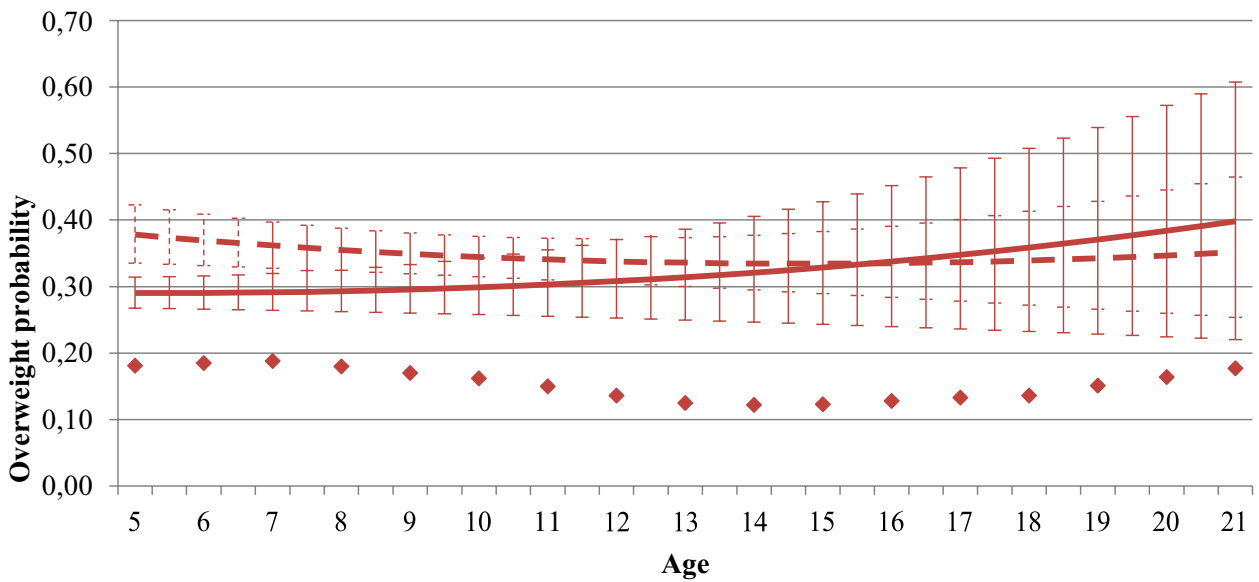


Fig. 2 Prediction of overweight probability in parents $(N=998$ assessments, derived from 655 parents). Error bars represent 95\% confidence interval for predicted probabilities. Population prevalence of being overweight was derived from the Dutch Health Survey 2014

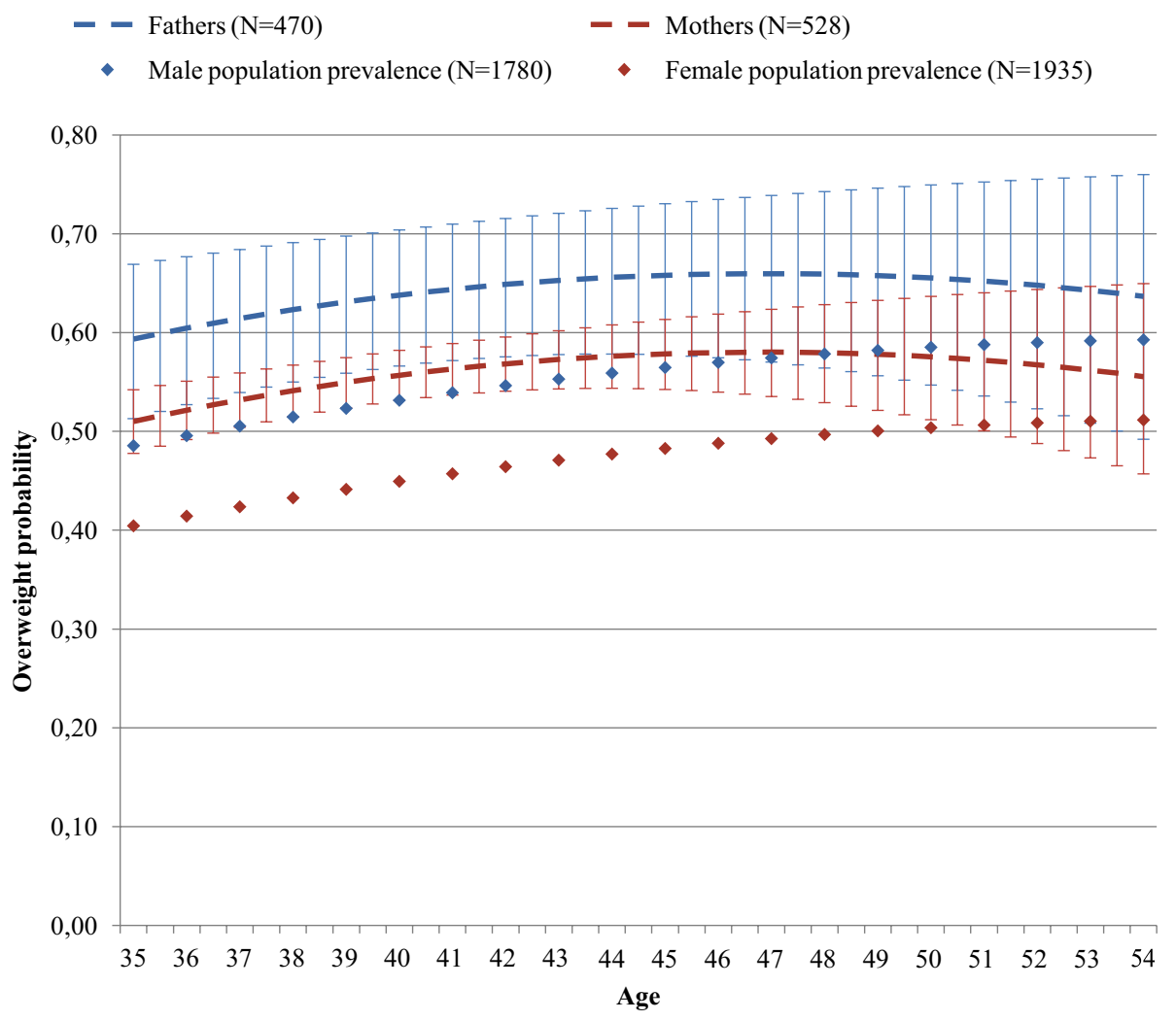

parent assessments from $N=447$ unique families. Results indicated that individuals with ADHD showed overweight at an increased prevalence when compared to the general population and the control cohort, but not when compared to their unaffected siblings. Unaffected siblings, mothers, and fathers of individuals with ADHD were just as likely to be overweight as their family member with ADHD. Parental overweight—but not parental ADHD—was predictive of offspring overweight. Age, gender, use of psychostimulants, antipsychotics, and melatonin did not predict the risk for being overweight in ADHD-affected individuals.

Results of the current study suggest that increased prevalence rates of being overweight in ADHD-affected individuals $[1,2,45-47]$ are likely based on factors shared in families. Similar to the results of a large case registry study which showed increased risk for ADHD in families with at least one family member being overweight [5], our study showed an increased risk for overweight in families with at least one family member with ADHD. Thus, there seems to be a common cause in the family environment rather than a causal relationship between ADHD and overweight. This is not in line with a recent review on ADHD and overweight [24], hypothesizing that the association between ADHD and overweight may be primarily linked to deficits in hot executive functions, characterized by impulsivity and difficulties in postponing gratification. The results are in line with another study suggesting the association between ADHD and overweight was completely explained by cumulative psychosocial risks [19]. Prime candidate environmental factors that increase the risk for both ADHD and overweight and that are shared by family members include inadequate health behaviors, foremost poor nutritional habits and lack of physical activity [48-51] as well as chronic stress [19]. Poor nutritional habits, lack of physical activity, and chronic stress tend to cluster with each other and within families [19], particularly in families with disadvantaged backgrounds [52]. Each of these factors is known to have direct (enhanced eating) and indirect detrimental effects on weight, and more broadly on physical and mental health [21, 29, 53], e.g., by impacting inflammatory and immune systems and subcellular metabolism [54].

In addition to inadequate health behaviors, genetic factors shared by family members may also account for the link at a population level between ADHD and overweight. Candidate gene studies [15-17] and large-scale genetic correlation based on genome-wide association studies of common genetic variants [18] have shown that genetic factors influencing, e.g., food responsiveness, cognitive and emotional control, dopamine neurotransmission, and circadian rhythm may increase the risk for ADHD and overweight. These variants are likely more prevalent in families where ADHD and/or overweight are present and may explain why some family members develop ADHD, others overweight and others a combination of both. So common genes may 
be partly responsible for an obesogenic family environment (e.g., lack of parental structuring and guidance [55]) and this same environment increases the risk for ADHD [56, 57]. A recent study suggest that potential genetic mechanisms underlying the association between ADHD and overweight may be sex specific and more pronounced in females than males [13]. However, the current findings were not moderated by sex and suggest that there is a risk of overestimating the association between ADHD and weight since no association between ADHD and overweight was present when correcting for the combined genetic and environmental factors that are shared between affected and unaffected family members. Future work in twin studies may further tease apart the genetic and shared environmental influences accounting for the association between the two phenotypes. It has further been shown recently that gene $\times$ environment interactions are of increasing importance for BMI with increasing age [58]. Taking into account both the genetic background and environmental influences in future studies is crucial for a better understanding of the development of overweight and ADHD within families.

Although previous studies reported a negative association between psychostimulant use and BMI [26, 27], our study did not find support for this association. This may suggest that reducing ADHD symptoms with pharmacological treatment is not an effective treatment for overweight status as has been hypothesized previously [59]. Unexpectedly, the use of antipsychotics (known obesogenic medication [60, 61]) was not associated with an increased risk for being overweight either. A potential explanation is that weight gain is a well-known side effect of this medication [28]; individuals at risk for being overweight might, therefore, be less likely to be prescribed antipsychotic or sleep medication, and/or their nutritional patterns might be more strictly monitored. In this study, medication use covered the 4 months prior to assessment but not the time period before, making it possible that the effect of medication on overweight may have been underestimated. It may also be argued that the effect of medication on BMI is small and not likely to make the difference between overweight versus a healthy weight; our dichotomous outcome measure may have reduced the chance of finding an association.

Strengths of the study include the large, family-based cohort allowing for within-family comparisons of the relationship between ADHD and being overweight. Thorough diagnostic data were available for all youth; height and weight were obtained through reliable direct measurements rather than through self-report. Both population prevalence data and a control group were used for comparisons, yielding similar results. As a potential weakness, fewer parental data than offspring data were available since parents were not assessed at all time points.
However, results for the subsample with parent data available were fully consistent with the results of the larger sample, indicating that the subsample with parental data was representative of the full sample. Parental ADHD was recorded using self-report, which is less optimal compared to structured diagnostic assessment. Nevertheless, results for parental ADHD data on overweight (i.e., no relationship) were fully in line with the absence of an association between ADHD and overweight in youth using thorough diagnostic procedures for ADHD. Also, several predictors (diagnosis, medication) as well as the outcome measure (overweight) were dichotomized for the purpose of potentially having a clear-cut message based on clinically meaningful variables. Dichotomous predictors and outcome may reduce the chances of finding more subtle effects due to loss of information, yet the large sample size makes it unlikely that this explains the absence of an association between ADHD and being overweight within families. Thereby, comorbid conditions (like depression) associated with overweight were not included in the analyses. However, this does not alter the absence of an association between ADHD and overweight within families.

In conclusion, our results indicate that being overweight runs in ADHD families, yet is not specifically linked to ADHD within these families. Inadequate health behaviors such as poor nutritional habits, lack of physical activity, or chronic stress as well as genetic factors shared by family members likely explain the findings. Gene $\times$ environment interaction studies including inadequate health behaviors and chronic stress on mental and physical health should be an important research priority. Given the profound negative health consequences of being overweight, more attention to intervention strategies targeting inadequate health behaviors in families of children with ADHD is a clinically important issue.

Acknowledgements This study used the sample from the NeuroIMAGE project. NeuroIMAGE was performed between 2009 and 2012, and is the follow-up study of the Dutch part of the International Multisite ADHD Genetics (IMAGE) project, a multisite, international effort. Funding support for the IMAGE Project was provided by National Institutes of Health (NIH) Grants R01MH62873 and R01MH081803 to Dr. Faraone. The follow-up and extension studies were supported by the Dutch Organization for Scientific Research (Nederlandse Organisatie voor Wetenschappelijk Onderzoek; NWO Large Investment Grant 1750102007010 and NWO Brain \& Cognition an Integrative Approach Grant (433-09-242) to Dr. Buitelaar), and Grants from Radboud University Nijmegen Medical Center, University Medical Center Groningen and Accare, and Free University (Vrije Universiteit, VU) Amsterdam. The research leading to these results also received funding from the European Community's Seventh Framework Programme (FP7/2007-2013) under Grant agreement number 278948 (TACTICS) and from the European Community's Horizon 2020 Programme under Grant agreement number 667302 (CoCA). Barbara Franke is supported by a personal Vici Grant from the NWO (016-130-669). 


\section{Compliance with ethical standards}

Conflict of interest All authors declare that they have no conflict of interest.

Ethical standards The authors assert that all procedures contributing to this work comply with the ethical standards of the relevant national and institutional committees on human experimentation and with the Helsinki Declaration of 1975, as revised in 2008. All procedures involving human subjects/patients were approved by the regional ethics committee (Centrale Commissie Mensgebonden Onderzoek: CMO Regio Arnhem Nijmegen; 2008/163; ABR: NL23894.091.08) and the medical ethical committee of the VU University Medical Center. Written informed consent was obtained from all subjects/patients [30].

Open Access This article is distributed under the terms of the Creative Commons Attribution 4.0 International License (http://creativeco mmons.org/licenses/by/4.0/), which permits unrestricted use, distribution, and reproduction in any medium, provided you give appropriate credit to the original author(s) and the source, provide a link to the Creative Commons license, and indicate if changes were made.

\section{References}

1. Nigg JT, Johnstone JM, Musser ED, Long HG, Willoughby MT, Shannon J (2016) Attention-deficit/hyperactivity disorder (ADHD) and being overweight/obesity: new data and metaanalysis. Clin Psychol Rev 43:67-79. https://doi.org/10.1016/j. cpr.2015.11.005

2. Cortese S, Moreira-Maia CR, St Fleur D, Morcillo-Penalver C, Rohde LA, Faraone SV (2016) Association between ADHD and Obesity: a systematic review and meta-analysis. Am J Psychiatry 173(1):34-43. https://doi.org/10.1176/appi.ajp.2015.15020266

3. Erhart M, Herpertz-Dahlmann B, Wille N, Sawitzky-Rose B, Holling H, Ravens-Sieberer U (2012) Examining the relationship between attention-deficit/hyperactivity disorder and overweight in children and adolescents. Eur Child Adolesc Psychiatry 21(1):3949. https://doi.org/10.1007/s00787-011-0230-0

4. Chen AY, Kim SE, Houtrow AJ, Newacheck PW (2010) Prevalence of obesity among children with chronic conditions. Obesity (Silver Spring) 18(1):210-213. https://doi.org/10.1038/ oby. 2009.185

5. Chen Q, Kuja-Halkola R, Sjolander A, Serlachius E, Cortese S, Faraone SV, Almqvist C, Larsson H (2017) Shared familial risk factors between attention-deficit/hyperactivity disorder and overweight/obesity - a population-based familial coaggregation study in Sweden. J Child Psychol Psychiatry 58(6):711-718. https://doi. org/10.1111/jcpp.12686

6. Cortese S, Bernardina BD, Mouren MC (2007) Attention-deficit/hyperactivity disorder (ADHD) and binge eating. Nutr Rev 65(9):404-411

7. Owens J, Gruber R, Brown T, Corkum P, Cortese S, O'Brien L, Stein M, Weiss M (2013) Future research directions in sleep and ADHD: report of a consensus working group. J Atten Disord 17(7):550-564. https://doi.org/10.1177/1087054712457992

8. Vogel SW, Bijlenga D, Tanke M, Bron TI, van der Heijden KB, Swaab H, Beekman AT, Kooij JJ (2015) Circadian rhythm disruption as a link between attention-deficit/hyperactivity disorder and obesity? J Psychosom Res 79(5):443-450. https://doi. org/10.1016/j.jpsychores.2015.10.002
9. Mikami AY, Hinshaw SP, Arnold LE, Hoza B, Hechtman L, Newcorn JH, Abikoff HB (2010) Bulimia nervosa symptoms in the multimodal treatment study of children with ADHD. Int J Eat Disord 43(3):248-259. https://doi.org/10.1002/eat.20692

10. Seitz J, Kahraman-Lanzerath B, Legenbauer T, Sarrar L, Herpertz S, Salbach-Andrae H, Konrad K, Herpertz-Dahlmann B (2013) The role of impulsivity, inattention and comorbid ADHD in patients with bulimia nervosa. PLoS One 8(5):e63891. https:// doi.org/10.1371/journal.pone.0063891

11. Davis C, Patte K, Levitan RD, Carter J, Kaplan AS, Zai C, Reid C, Curtis C, Kennedy JL (2009) A psycho-genetic study of associations between the symptoms of binge eating disorder and those of attention deficit (hyperactivity) disorder. J Psychiatry Res 43(7):687-696. https://doi.org/10.1016/j.jpsychires.2008.10.010

12. Seitz J, Hueck M, Dahmen B, Schulte-Ruther M, Legenbauer T, Herpertz-Dahlmann B, Konrad K (2016) Attention network dysfunction in bulimia nervosa-an fMRI study. PLoS One 11(9):e0161329. https://doi.org/10.1371/journal.pone.0161329

13. Do EK, Haberstick BC, Williams RB, Lessem JM, Smolen A, Siegler IC, Fuemmeler BF (2019) The role of genetic and environmental influences on the association between childhood ADHD symptoms and BMI. Int J Obes (Lond) 43(1):33-42. https://doi. org/10.1038/s41366-018-0236-5

14. Capusan AJ, Yao S, Kuja-Halkola R, Bulik CM, Thornton LM, Bendtsen P, Marteinsdottir I, Thorsell A, Larsson H (2017) Genetic and environmental aspects in the association between attention-deficit hyperactivity disorder symptoms and bingeeating behavior in adults: a twin study. Psychol Med. https://doi. org/10.1017/s0033291717001416

15. Albayrak O, Putter C, Volckmar AL, Cichon S, Hoffmann P, Nothen MM, Jockel KH, Schreiber S, Wichmann HE, Faraone SV, Neale BM, Herpertz-Dahlmann B, Lehmkuhl G, Sinzig J, Renner TJ, Romanos M, Warnke A, Lesch KP, Reif A, Schimmelmann BG, Scherag A, Hebebrand J, Hinney A, Psychiatric GCAS (2013) Common obesity risk alleles in childhood attention-deficit/ hyperactivity disorder. Am J Med Genet Part B Neuropsychiatric Genet 162B(4):295-305. https://doi.org/10.1002/ajmg.b.32144

16. Blum K, Sheridan PJ, Wood RC, Braverman ER, Chen TJ, Comings DE (1995) Dopamine D2 receptor gene variants: association and linkage studies in impulsive-addictive-compulsive behaviour. Pharmacogenetics 5(3):121-141

17. Velders FP, De Wit JE, Jansen PW, Jaddoe VW, Hofman A, Verhulst FC, Tiemeier H (2012) FTO at rs9939609, food responsiveness, emotional control and symptoms of ADHD in preschool children. PLoS One 7(11):e49131. https://doi.org/10.1371/journ al.pone. 0049131

18. Anttila V, Bulik-Sullivan B, Finucane HK, Bras J, Duncan L, Escott-Price V, Falcone G, Gormley P, Malik R, Patsopoulos N, Ripke S, Walters R, Wei Z, Yu D, Lee P, Breen G, Bulik C, Daly M, Dichgans M, Faraone S, Guerreiro R, Holmans P, Kendler K, Koeleman B, Mathews C, Scharf J, Sklar P, Williams J, Wood N, Cotsapas C, Palotie A, Smoller J, Sullivan P, Rosand J, Corvin A, Neale B (2016) Analysis of shared heritability in common disorders of the brain. bioRxiv. https://doi.org/10.1101/048991

19. Pauli-Pott U, Reinhardt A, Bagus E, Wollenberg B, Schroer A, Heinzel-Gutenbrunner M, Becker K (2016) Psychosocial risk factors underlie the link between attention deficit hyperactivity symptoms and overweight at school entry. Europ Child Adolesc Psychiatry. https://doi.org/10.1007/s00787-016-0870-1

20. Holton KF, Nigg JT (2016) The association of lifestyle factors and ADHD in children. J Attent Disord 1:1. https://doi. org/10.1177/1087054716646452

21. Reilly JJ, Armstrong J, Dorosty AR, Emmett PM, Ness A, Rogers I, Steer C, Sherriff A, Avon Longitudinal Study of P, Children Study T (2005) Early life risk factors for obesity in childhood: 
cohort study. BMJ 330(7504):1357. https://doi.org/10.1136/ bmj.38470.670903.e0

22. Pugh SJ, Hutcheon JA, Richardson GA, Brooks MM, Himes KP, Day NL, Bodnar LM (2016) Gestational weight gain, prepregnancy body mass index and offspring attention-deficit hyperactivity disorder symptoms and behaviour at age 10. BJOG. https://doi. org/10.1111/1471-0528.13909

23. Jo H, Schieve LA, Sharma AJ, Hinkle SN, Li R, Lind JN (2015) Maternal prepregnancy body mass index and child psychosocial development at 6 years of age. Pediatrics 135(5):e1198-e1209. https://doi.org/10.1542/peds.2014-3058

24. Hanc T, Cortese S (2018) Attention deficit/hyperactivity-disorder and obesity: a review and model of current hypotheses explaining their comorbidity. Neurosci Biobehav Rev 92:16-28. https://doi. org/10.1016/j.neubiorev.2018.05.017

25. Byrd HC, Curtin C, Anderson SE (2013) Attention-deficit/ hyperactivity disorder and obesity in US males and females, age 8-15 years: national Health and Nutrition Examination Survey 2001-2004. Pediatr Obes 8(6):445-453. https://doi.org/10.111 $1 / \mathrm{j} .2047-6310.2012 .00124 . x$

26. Schwartz BS, Bailey-Davis L, Bandeen-Roche K, Pollak J, Hirsch AG, Nau C, Liu AY, Glass TA (2014) Attention deficit disorder, stimulant use, and childhood body mass index trajectory. Pediatrics 133(4):668-676. https://doi.org/10.1542/peds.2013-3427

27. Poulton AS, Melzer E, Tait PR, Garnett SP, Cowell CT, Baur LA, Clarke S (2013) Growth and pubertal development of adolescent boys on stimulant medication for attention deficit hyperactivity disorder. Med J Aust 198(1):29-32

28. Ganguli R (1999) Weight gain associated with antipsychotic drugs. J Clin Psychiatry 60(Suppl 21):20-24

29. van Egmond-Frohlich AW, Widhalm K, de Zwaan M (2012) Association of symptoms of attention-deficit/hyperactivity disorder with childhood overweight adjusted for confounding parental variables. Intern J Obes 36(7):963-968. https://doi.org/10.1038/ ijo. 2012.78

30. von Rhein D, Mennes M, van Ewijk H, Groenman AP, Zwiers MP, Oosterlaan J, Heslenfeld D, Franke B, Hoekstra PJ, Faraone SV, Hartman C, Buitelaar J (2015) The NeuroIMAGE study: a prospective phenotypic, cognitive, genetic and MRI study in children with attention-deficit/hyperactivity disorder. Design and descriptives. Eur Child Adolesc Psychiatry 24(3):265-281. https://doi. org/10.1007/s00787-014-0573-4

31. Conners C, Sitarenios G, Parker J, Epstein J (1998) The revised Conners' Parent Rating Scale (CPRS-R): factor structure, reliability, and criterion validity. J Abnorm Child Psychol 26(4):257-268

32. Conners C, Erhardt D, Sparrow E (1999) Conner's adult ADHD Rating Scales: CAARS. Multi-Health Syst, North Tonawanda

33. Conners C, Sitarenios G, Parker J, Epstein J (1998) Revision and restandardization of the Conners Teacher Rating Scale (CTRS-R): factor structure, reliability, and criterion validity. J Abnorm Child Psychol 26(4):279-291

34. Kaufman J, Birmaher B, Brent D, Rao U, Flynn C, Moreci P, Williamson D, Ryan N (1997) Schedule for affective disorders and schizophrenia for school-age children-present and lifetime version (K-SADS-PL): initial reliability and validity data. J Am Acad Child Adolesc Psychiatry 36(7):980-988. https://doi. org/10.1097/00004583-199707000-00021

35. Sandra Kooij JJ, Marije Boonstra A, Swinkels SH, Bekker EM, de Noord I, Buitelaar JK (2008) Reliability, validity, and utility of instruments for self-report and informant report concerning symptoms of ADHD in adult patients. J Atten Disord 11(4):445-458. https://doi.org/10.1177/1087054707299367

36. Khosla T, Lowe CR (1967) Indices of obesity derived from body weight and height. Br J Preven Soc Med 21(3):122-128

37. Cole TJ, Flegal KM, Nicholls D, Jackson AA (2007) Body mass index cut offs to define thinness in children and adolescents: international survey. BMJ 335(7612):194. https://doi.org/10.1136/ bmj.39238.399444.55

38. Dinsdale H, Ridler C, Ells L (2011) A simple guide to classifying body mass index in children. Natl Obes Obs, Oxford

39. Schonbeck Y, Talma H, van Dommelen P, Bakker B, Buitendijk SE, Hirasing RA, van Buuren S (2011) Increase in prevalence of overweight in Dutch children and adolescents: a comparison of nationwide growth studies in 1980, 1997 and 2009. PLoS One 6(11):e27608. https://doi.org/10.1371/journal.pone.0027608

40. Gezondheidsenquête 2014 (2014-10). Centraal Bureau voor de Statistiek (CBS)

41. Groenman AP, Oosterlaan J, Greven CU, Vuijk PJ, Rommelse N, Franke B, Hartman CA, Hoekstra PJ, Sergeant J, Faraone SV, Buitelaar J (2015) Neurocognitive predictors of substance use disorders and nicotine dependence in ADHD probands, their unaffected siblings, and controls: a 4-year prospective follow-up. J Child Psychol Psychiatry 56(5):521-529. https:// doi.org/10.1111/jcpp. 12315

42. van der Meer D, Hoekstra PJ, Zwiers M, Mennes M, Schweren LJ, Franke B, Heslenfeld DJ, Oosterlaan J, Faraone SV, Buitelaar JK, Hartman CA (2015) Brain correlates of the interaction between 5-HTTLPR and psychosocial stress mediating attention deficit hyperactivity disorder severity. Am J Psychiatry 172(8):768-775. https://doi.org/10.1176/appi.ajp.2015.14081 035

43. Buis M (2009) Scaling levels of education. Faculty of social sciences. VU-University Amsterdam, Amsterdam

44. Benjamini Y, Hochberg Y (2000) On the adaptive control of the false discovery rate in multiple testing with independent statistics. J Educ Behav Stat 25(1):60-83. https://doi.org/10.2307/1165312

45. Korczak DJ, Lipman E, Morrison K, Duku E, Szatmari P (2014) Child and adolescent psychopathology predicts increased adult body mass index: results from a prospective community sample. J Dev Behav Pediatr 35(2):108-117. https://doi.org/10.1097/ DBP.0000000000000015

46. Cortese S, Faraone SV, Bernardi S, Wang S, Blanco C (2013) Adult attention-deficit hyperactivity disorder and obesity: epidemiological study. Br J Psychiatry 203(1):24-34. https://doi. org/10.1192/bjp.bp.112.123299

47. Fliers EA, Buitelaar JK, Maras A, Bul K, Hohle E, Faraone SV, Franke B, Rommelse NN (2013) ADHD is a risk factor for overweight and obesity in children. J Dev Behav Pediatr 34(8):566574. https://doi.org/10.1097/DBP.0b013e3182a50a67

48. Birch LL, Davison KK (2001) Family environmental factors influencing the developing behavioral controls of food intake and childhood overweight. Pediatr Clin N Am 48(4):893-907

49. Faith MS, Scanlon KS, Birch LL, Francis LA, Sherry B (2004) Parent-child feeding strategies and their relationships to child eating and weight status. Obes Res 12(11):1711-1722. https://doi. org/10.1038/oby.2004.212

50. Moore LL, Lombardi DA, White MJ, Campbell JL, Oliveria SA, Ellison RC (1991) Influence of parents' physical activity levels on activity levels of young children. J Pediatr 118(2):215-219

51. Wu X, Ohinmaa A, Veugelers PJ (2016) The influence of health behaviours in childhood on attention deficit and hyperactivity disorder in adolescence. Nutrients. https://doi.org/10.3390/nu812 0788

52. Kim EJ, Kwon HJ, Ha M, Lim MH, Oh SY, Kim JH, Yoo SJ, Paik KC (2014) Relationship among attention-deficit hyperactivity disorder, dietary behaviours and obesity. Child Care Health Dev 40(5):698-705. https://doi.org/10.1111/cch.12129

53. Blair NJ, Thompson JM, Black PN, Becroft DM, Clark PM, Han DY, Robinson E, Waldie KE, Wild CJ, Mitchell EA (2007) Risk factors for obesity in 7-year-old European children: the Auckland Birthweight Collaborative Study. Arch Dis Child 92(10):866-871. https://doi.org/10.1136/adc.2007.116855 
54. Lemche E, Chaban OS, Lemche AV (2016) Neuroendorine and epigenetic mechanisms subserving autonomic imbalance and HPA dysfunction in the metabolic syndrome. Front Neurosci 10:142. https://doi.org/10.3389/fnins.2016.00142

55. Schmeer KK (2012) Family structure and obesity in early childhood. Soc Sci Res 41(4):820-832. https://doi.org/10.1016/j.ssres earch.2012.01.007

56. Banerjee TD, Middleton F, Faraone SV (2007) Environmental risk factors for attention-deficit hyperactivity disorder. Acta Paediatrica (Oslo, Norway: 1992) 96(9):1269-1274. https://doi.org/10.1 111/j.1651-2227.2007.00430.x

57. Biederman J, Milberger S, Faraone SV, Kiely K, Guite J, Mick E, Ablon S, Warburton R, Reed E (1995) Family-environment risk factors for attention-deficit hyperactivity disorder. A test of Rutter's indicators of adversity. Arch Gen Psychiatry 52(6):464-470

58. Silventoinen K, Jelenkovic A, Sund R, Hur YM, Yokoyama Y, Honda C, Hjelmborg JV, Moller S, Ooki S, Aaltonen S, Ji F, Ning F, Pang Z, Rebato E, Busjahn A, Kandler C, Saudino KJ, Jang KL, Cozen W, Hwang AE, Mack TM, Gao W, Yu C, Li L, Corley RP, Huibregtse BM, Christensen K, Skytthe A, Kyvik KO, Derom CA, Vlietinck RF, Loos RJ, Heikkila K, Wardle J, Llewellyn CH, Fisher A, McAdams TA, Eley TC, Gregory AM, He M, Ding X, Bjerregaard-Andersen M, Beck-Nielsen H, Sodemann M, Tarnoki AD, Tarnoki DL, Stazi MA, Fagnani C, D’Ippolito C, Knafo-Noam A, Mankuta D, Abramson L, Burt SA, Klump KL, Silberg JL, Eaves LJ, Maes HH, Krueger RF, McGue M, Pahlen
S, Gatz M, Butler DA, Bartels M, van Beijsterveldt TC, Craig JM, Saffery R, Freitas DL, Maia JA, Dubois L, Boivin M, Brendgen M, Dionne G, Vitaro F, Martin NG, Medland SE, Montgomery GW, Chong Y, Swan GE, Krasnow R, Magnusson PK, Pedersen NL, Tynelius P, Lichtenstein P, Haworth CM, Plomin R, Bayasgalan G, Narandalai D, Harden KP, Tucker-Drob EM, Oncel SY, Aliev F, Spector T, Mangino M, Lachance G, Baker LA, Tuvblad C, Duncan GE, Buchwald D, Willemsen G, Rasmussen F, Goldberg JH, Sorensen TI, Boomsma DI, Kaprio J (2016) Genetic and environmental effects on body mass index from infancy to the onset of adulthood: an individual-based pooled analysis of 45 twin cohorts participating in the COllaborative project of Development of Anthropometrical measures in Twins (CODATwins) study. Am J Clin Nutr. https://doi.org/10.3945/ajen.116.130252

59. Cortese S, Castellanos FX (2014) The relationship between ADHD and obesity: implications for therapy. Expert Rev Neurother 14(5):473-479. https://doi.org/10.1586/14737 175.2014.904748

60. Bak M, Fransen A, Janssen J, van Os J, Drukker M (2014) Almost all antipsychotics result in weight gain: a meta-analysis. PLoS One 9(4):e94112. https://doi.org/10.1371/journal.pone.0094112

61. Almandil NB, Liu Y, Murray ML, Besag FM, Aitchison KJ, Wong IC (2013) Weight gain and other metabolic adverse effects associated with atypical antipsychotic treatment of children and adolescents: a systematic review and meta-analysis. Paediatr Drugs 15(2):139-150. https://doi.org/10.1007/s40272-013-0016-6 